\title{
La ciudad como símbolo de totalidad en el mundo del arte
}

\author{
Symbol of the city as a whole in the art world \\ BELÉN LEÓN DEL RÍo \\ Departamento de Escultura e Historia de las Artes Plásticas. \\ Facultad de Bellas Artes Santa Isabel de Hungría. Universidad de Sevilla \\ belenleon@us.es
}

Recibido: $21 / 01 / 2015$

Aceptado: 23/03/2015

\begin{abstract}
Resumen
Durante el proceso creativo habría una propensión del artista a crear símbolos, siendo la manifestación artística un vehículo para expresarlos, ya que, en ella encontramos imágenes y asociaciones que son análogas a las ideas, mitos y ritos primitivos donde la ciudad adquiere un gran protagonismo al ser un símbolo que representaría la totalidad psíquica. En el arte plástico la ciudad adquiere un significado de integridad que uniría en sí los contrastes, este concepto psicológico aparecería espontáneamente y se relacionaría con otros arquetipos específicos reconocibles sobre todo en la forma del mandala y sus numerosas variantes, tratándose de símbolos de transformación que estarían demandando la necesidad de liberar al ser humano del estado actual en el que se encuentra.
\end{abstract}

\section{Palabras clave}

Inconsciente, círculo, mandala, supraconsciente, símbolo, arquetipo. 


\begin{abstract}
During the creative process would have a propensity artist to create symbols, being the artistic expression a vehicle to express, because in it we find images and associations that are analogous to those ideas, myths and primitive rites where the city takes on a major role to be a symbol that would represent the psychic totality. In the visual arts the city acquires a meaning of integrity that would unite itself the contrasts, this psychological concept would appear spontaneously and relate to other recognizable specific archetypes especially in the form of the mandala and its many variants, being symbols of transformation that would claiming the need to free the human from the current state in which it is being.
\end{abstract}

\title{
Keywords
}

Unconscious, circle, mandala, superconscious, symbol, archetype.

Referencia normalizada: LEÓN DEL RíO, B. (2015): “La ciudad como símbolo de totalidad en el mundo del arte". Arte y Ciudad. Revista de Investigación, nº 7 (abril), págs. 6796. Madrid. Grupo de Investigación Arte, Arquitectura y Comunicación en la Ciudad Contemporánea, Universidad Complutense de Madrid.

Sumario: 1.- El simbolismo del mandala y la ciudad. 2.- La ciudad como elemento unificador. 3.- El cuadrado y el trazado de la ciudad. 4.- Símbolos transcendentales ligados a la ciudad. 5.- La ciudad como símbolo social y divino relacionado con la cuaternidad como imagen del mundo interior del ser humano. 6.- La unión de los contrarios y la ciudad. 7.- Referencias bibliográficas.

\section{El simbolismo del mandala y la ciudad.}

Los estudiosos de la psicología profunda, más que los historiadores o los arqueólogos, han buscando el significado de los mitos y los símbolos, como refleja la obra Tóten y Tabú (1912) de Freud junto con las obras de C. G. Jung, este último concebía un inconsciente universal al que denominó inconsciente colectivo, descubriendo una simbología perteneciente a las más antiguas tradiciones sagradas que se repetía en todas las culturas y que estaba relacionada con los periodos de transición en la vida del individuo. Estas imágenes son autóctonas y de uniformidad relativamente grande, apareciendo perfeccionadas y envueltas en formas racionales en las grandes religiones del mundo. 
C. G. Jung ya había aceptado anteriormente la idea de Freud de que en el inconsciente se hallaban reliquias de antiguas experiencias. Sueños personales de este autor y sus vivencias del inconsciente le llevaron a la opinión de que estos restos no eran, sin embargo, formas muertas, sino que formaban parte de la psiquis viva. Sus posteriores investigaciones confirmaron esta hipótesis y en el transcurso de los años surgió de ella la teoría de los arquetipos. Este autor afirmaba:

En estas formas arquetípicas se expresa algo vinculado, por lo menos con la misteriosa esencia de una psique natural, es decir con la esencia de un factor cósmico de primer orden. En bien de la rehabilitación de la psique objetiva, desvalorizada por la hipertrofia moderna de la consciencia, siempre debo volver a insistir en que sin psique no se puede sentar la existencia de mundo alguno, y menos aún conocerlo. De acuerdo con todo lo que sabemos, es seguro que la psique primitiva no posee todavía consciencia alguna de sí. La consciencia sólo se constituyó en el curso de la evolución, que en parte tiene lugar en la época histórica (Jung, 1992: 122).

C. G. Jung señala que no hay cultura primitiva que no posea un sistema de enseñanzas secretas y de sabiduría, que las sociedades de hombres y los clanes totémicos preservan, al igual que hacían en la antigüedad con sus misterios y su mitología. Autores como Sri Aurobindo ya mencionan como las sociedades humanas en sus primeros comienzos o en fases primitivas solían tener una mentalidad marcadamente simbólica que impregnaba sus pensamientos, costumbres e instituciones, este estadio de su desarrollo social era siempre religioso y activamente imaginativo en su religión, pues para este autor existe un parentesco natural entre simbolismo y el sentimiento generalizado, imaginativo o intuitivo, de modo que ambos van siempre a la par:

El símbolo expresa, pues, algo que el hombre siente que está presente detrás de sí mismo, de su vida y de sus actividades: el Divino, los dioses, el vasto y el profundo Inefable, una naturaleza de las cosas oculta, viva y misteriosa (Aurobindo, 2002: 22).

A. Jaffé hace un estudio del simbolismo en las artes visuales, examinando el motivo del mandala ligado a la ciudad por su carácter sagrado. Para esta autora la ciudad con planta en forma de mandala sería la proyección de una imagen arquetípica que surgiría del inconsciente del ser humano hacia el ex- 
terior. Así, en fundaciones clásicas o primitivas, el plano mandala no sería trazado por consideraciones estéticas o económicas:

Fue la transformación de la ciudad en un cosmos ordenado, un lugar sagrado vinculado por su centro con el otro mundo. Y esa transformación armoniza con los sentimientos vitales y las necesidades del hombre religioso (Jaffé, 1997: 244).

La ciudad como símbolo adquiere un carácter sagrado que influirá en la configuración de las ciudades antiguas donde la geomancia juega un papel de gran importancia, ayudando a elegir el sitio donde debía ser establecida la ciudad según la convergencia de los vientos, de las aguas o de las corrientes telúricas o la disposición de la sombra y de la luz, tratando de la determinación de las influencias que permitían al individuo vivir en armonía con su entorno natural. La geomancia fue heredada de la época neolítica y conocida por los celtas, Roma y Bizancio, siendo primitivamente usada en China como hing- $f a$ "arte de las formas y de las situaciones", sirviendo como hemos visto no sólo para determinar el plan, la orientación y la forma de las ciudades, sino también de las fortificaciones, las casas, las tumbas e incluso las reglas de la táctica o de la estrategia.

En la construcción de las ciudades, también desempeñaría un papel considerable la astrología, reflejando los movimientos del sol y los astros, fijándolos mediante el trazado de planos, ejemplo de ello sería la coincidencia a menudo de estos planos con las posiciones de la Osa Mayor:

En Roma, como en la China, en la India o en Angkor, el plano de la ciudad se establece con la ayuda del gnomon. Estando la ciudad en el centro, el gnomon no debe dar sombra en la mitad del verano (Chevalier, 1999: 309).

E. Pérez de Carrera (2004: 224-225) nos acerca a estos espacios míticos:

Se construyeron geometrías sagradas en base a números de longitud infinita. Espacios cabalizados con números transcendentes y medidas irracionales fueron cuna de nuevas músicas y nuevos estados, que pretendieron reproducir arquetipos de mundos interiores en los que el hombre se viera como una célula situada en un espacio en que las fuerzas telúricas y las líneas que rompen el aire provocaran sensaciones escondidas que alteran la consciencia. Se construyeron laberintos, configuraciones mandálicas que sirvieran de modelo a marchas y bailes rituales en los que jugaban las energías que ruedan por la Tierra (corrientes, absorciones, empujes, etcétera) en su relación con el Cosmos, y se orientaron en las rutas del Sol o en las del tiempo hacia momentos astronómicos especiales como los solsticios. 
Para A. Jaffé el mandala sería un símbolo de gran importancia en la arquitectura de todas las civilizaciones, formando no sólo la planta de edificios seculares y sagrados, sino también tendría una gran significación en la urbanización clásica, medieval e incluso en la urbanización de hoy en día. Pone de ejemplo el relato que hace Plutarco de la fundación de Roma, donde sus habitantes asimilaron los mitos de los pueblos conquistados, pero esta cultura consideró una serie de mitos como claramente romanos, siendo el más conocido el de la fundación de Roma:

Según Plutarco, Rómulo envió a buscar constructores a Etruria para que le instruyeran en las costumbres sacras y escribieran las normas acerca de todas las ceremonias que habrían de observarse en la misma forma "que los misterios". Primeramente cavaron un hoyo circular, donde el Comitium, o Tribunal de la Asamblea, está hoy día, y en ese hoyo arrojaron ofrendas simbólicas de frutos de la tierra. Luego, cada hombre cogió un puñado de tierra del campo de donde procedía y los echaron mezclados en el hoyo. Al hoyo se le dio el nombre de mundus (que también significa cosmos). Alrededor de él Rómulo trazó en círculo los límites de la ciudad con un arado arrastrado por un toro y una vaca. Allí donde se proyectaba una puerta, levantaba la reja del arado y el arado pasaba de largo (Jaffé, 1997: 243).

Los habitantes del imperio consideraban a Roma ciudad sagrada, al igual que la demarcación de sus límites igualmente sagrados. Esta autora señala como la ciudad fundada con esta ceremonia solemne era de forma circular aunque la antigua descripción de Roma sería urbs quadrata, la ciudad cuadrada. Una teoría intentaría reconciliar esta contradicción diciendo que la palabra quadrata se entendería como "cuatripartita", de forma que la ciudad circular se dividió en cuatro partes por dos arterias principales que irían de norte a sur y de oeste a este, habiendo un punto de intersección que coincidiría con el mundus como menciona Plutarco. El mundus se consideraba el centro que enlazaba la ciudad con el mundo de los espíritus, al igual que el cordón umbilical enlazaría al niño con la madre.

Plutarco concebiría a Roma como circular y cuadrada, ya que antes de relatar la ceremonia circular de la fundación de la ciudad realizada por Rómulo, Plutarco también menciona a la ciudad, como Roma quadrata, es decir cuadrada. Otra teoría demuestra que esta aparente contradicción no debía entenderse más que como un símbolo, es decir, como la representación del problema 
matemáticamente irresoluble de la cuadratura del círculo, esta se produciría por la división efectuada por los dos diámetros perpendiculares.

Para A. Jaffé en las dos teorías estaría implicado el símbolo del mandala, señalando como la afirmación de Plutarco de que la fundación de la ciudad fue enseñada por los etruscos en la misma forma que se hacía en los misterios, mediante rito secreto:

Con su plano mandala, la ciudad, y sus habitantes, se exalta sobre el mero reino secular. Esto se subraya aún más por el hecho de que la ciudad tiene un centro, el mundus, que establece la relación de la ciudad con el "otro" reino, la mansión de los espíritus ancestrales. (El mundus fue cubierto con una gran piedra llamada "piedra" del alma. La piedra se quitaba determinados días y luego, se decía, los espíritus de los muertos surgían del hoyo) (Jaffé, 1997: 244).

A. Jaffé afirma como algunas ciudades medievales fueron fundadas sobre planos de mandala, siendo rodeadas por murallas más o menos circulares, y divididas en "cuartos" mediante dos arterias principales, de manera que condujeran a las cuatro puertas, estando la iglesia o catedral en el punto de intersección de estas dos arterias:

La inspiradora de la ciudad medieval, con sus cuartos, era "la ciudad santa, Jerusalén" (según el Apocalipsis), que tiene planta cuadrangular y murallas y su número de puertas es tres veces cuatro. Pero Jerusalén no tenía templo en el centro porque la presencia inmediata de Dios era su centro. (El plano en forma de mandala para una ciudad no está en modo alguno pasado de moda. Un ejemplo moderno es la ciudad de Washington, capital de los Estados Unidos (Jaffé, 1997: 244).

Michael Maier en su tratado Circulus quadratus de 1616, compara la Jerusalén celestial con el lapis, al que representa como fortaleza de oro, mediante un círculo dividido en las oposiciones aristotélicas de elementos y cualidades, que a su vez fueron asimilados, de las formas más diversas, a los cuatro puntos cardinales. El lapis que las uniría a todas, simbolizaría el "omphalos" u ombligo del universo.

Para C. G. Jung en la simbólica alquimista, se expresa la problemática del proceso del devenir de la personalidad, al que llamó proceso de individuación, la idea central del lapis pilosophorum correspondería al "sí-mismo", el opus, con sus innumerables símbolos, que se representaría el proceso incons- 
ciente de individuación, al que define como el desarrollo gradual del sí desde un estado inconsciente a una toma de consciencia: "Por eso el lapis como representación de la materia de origen (materia prima), está tanto al comienzo como al final del proceso" (Jung, 1995: 277).

G. Champeaux señala como la combinación del círculo y el cuadrado evocaría una idea de movimiento, de cambio de orden o de plano:

La figura circular añadida a la figura cuadrada es espontáneamente interpretada por el psiquismo humano como la imagen dinámica de una dialéctica entre lo celestial transcendente, a lo cual el hombre aspira naturalmente, y lo terrenal donde él se sitúa actualmente, donde aprehende como sujeto de un pasaje que debe ya realizar desde ahora gracias al concurso de los signos (Chevalier y Gheerbrant, 1999: 302).

Estos arquetipos serían imágenes que irían acompañadas por una afectividad que impresionaría e influiría, teniendo una pre-forma inconsciente que según C. G. Jung, pertenecería a la estructura heredada de la psique. El mandala sería símbolo del centro, del objetivo y del "sí-mismo" como totalidad psíquica. Sería como la autorrepresentación de un proceso central, relacionado con la producción de un nuevo centro de la personalidad:

Los mandalas se presentan, según la experiencia... en situaciones que se caracterizan por su confusión o carácter enigmático. El arquetipo constelado de este modo representa un esquema de orden que en cierto modo se sitúa sobre el caos psicológico como retículo psicológico o como círculo dividido en cuatro partes, por medio de lo cual cada contenido asume su lugar y mantiene coherente el todo que tiende a dispersarse en lo indeterminado, por medio del círculo guardián y protector (Jung, 1996: 416).

\section{La ciudad como elemento unificador.}

C. G. Jung afirma como existiría un factor de guía interior distinto de la personalidad consciente al que denominó "sí-mismo" y que actuaría como centro regulador manifestándose en algunas ocasiones en los sueños. El "símismo" que define C. G. Jung sería como una magnitud que no corresponde a la desde siempre designada por el concepto de "yo", sino que la contendría como un concepto de mayor extensión, definiendo el "yo" como un factor complejo al que se refieren todos los contenidos de consciencia, que no puede 
ser como dice este autor exhaustivamente descrito. A raíz de sus investigaciones realizadas alrededor de la alquimia, descubrió que lo inconsciente era un proceso de evolución y que la relación del yo con los contenidos del inconsciente, producía una transformación o evolución de la psiquis. Este proceso de metamorfosis conduce a una creatividad peculiar en cada momento de la vida, que en el artista plástico se traduciría en reacciones creativas inesperadas que provienen de la unidad con el sí-mismo.

En cuanto resulta altamente verosímil que estemos más bien muy alejados aún de haber ascendido a la cumbre de la consciencia absoluta, cada cual es capaz todavía de una consciencia más amplia, por lo cual puede suponerse también que los procesos inconscientes llevan siempre y en todas partes a la consciencia contenidos que, si se reconocieran, agrandarían la amplitud consciente. Visto así, el inconsciente aparece como un ámbito de experiencia de indefinida extensión (Jung, 1993a: 82).

C. G. Jung afirma como el sí-mismo se realizaría por la concentración de lo múltiple en el centro, comparándolo con un "espejo", que por un lado reflejaría la consciencia subjetiva del individuo, haciendo visible a éste, de forma que no sólo reproduciría el hombre empírico sino lo mostraría como totalidad transcendental.

Así como se abre una "puerta" a la cual se golpea o se le aparece el "camino" al que lo busca, del mismo modo, para el que se vuelve hacía su centro (transcendental), comienza un proceso de conscielización y una evolución hacia la unidad y la totalidad. Ya no se ve como separado sino como uno. Sólo la consciencia subjetiva está separada. Pero si entra en relación con su centro se integra en el todo (Jung, 1992: 115).

C. G. Jung decía que en el inconsciente se producirían imágenes, tratándose principalmente de representaciones de carácter mandálico, es decir, de círculo y cuaternidad, siendo estás últimas las características más claras y más frecuentes de la representación de la ciudad, donde encontraremos elementos formales del mandala como el círculo, la espiral, la cuadratura del círculo o las figuras tetrádicas entre otras. Estas imágenes unirían los opuestos en la forma de cuaternario, como enlace en cruz, o expresan la totalidad por medio de la forma circular o esférica.

Según C. G. Jung estas representaciones serían anticipaciones de una totalidad que al principio sólo sería alcanzable aproximadamente, implicando 
una referencia al sí-mismo, que contendría y ordenaría dentro de sí todos los contrastes, constituyendo en primer lugar una mera indicación de un orden posible de la totalidad:

Lo que intenta expresar la alquimia mediante el rebis y la cuadratura del círculo, y el hombre moderno mediante las figuras del círculo, y la cuaternidad, significa una integridad que une en sí los contrastes, con lo cual, si no resuelve el conflicto, al menos le quita su agudeza (Jung, 1993b: 185).

Los artistas contemporáneos integran estos arquetipos mandálicos ligados a la ciudad como Enrich Reusch que en su obra Pavimento de 1980, diseñará esculturas de discos descentralizadas y vinculadas al suelo.

Activó, intensificó y amplió el entorno mediante plantillas, paneles, vigas y cubos colocados sobre el suelo. Incluso los intervalos juegan en lo que constituye a efectos prácticos una versión urbana del land art o al menos del arte "paisajista". (Schneckenburger, 1998: 530)

Tadashi Kawamata construiría pesadas instalaciones de madera, colocándolas en lugares públicos mediante la representación de espirales de madera para criticar la arquitectura, el arte y la ciudad, como podemos ver en su obra de 1987 titulada Proyecto de iglesia destruida, aquí la espiral se integraría en su obra relacionándose con el mandala y evocando la evolución de una fuerza o de un estado.

G. Champeaux afirma como la espiral manifestaría la aparición de un movimiento circular que saldría del punto original, manteniendo y prolongando este movimiento indefinidamente

... es el tipo de líneas sin fin que enlazan incesantemente las dos extremidades del devenir... (La espiral es y simboliza) emanación, extensión, desarrollo, continuidad cíclica pero en progreso y rotación creacional (Chevalier $\mathrm{y}$ Gheerbrant, 1999: 302).

Mientras que el cuadrado sería la figura básica del espacio, el círculo y particularmente la espiral, sería del tiempo. Así las edades del mundo, la vida humana o el mes lunar estarían ritmados por el cuaternario, mientras que las cuatro fases del movimiento cíclico se expresarían por el círculo. El artista americano Charles Simonds, instala ciudades en miniatura de un "pequeño pueblo" sobre los muros en ruinas de Lower Eatside, trazando estas construcciones en formas orgánicas, espirales, axiales y cuadrados como vemos en su obra titula- 
da Vivienda de 1975. M. Schneckenburge dice de las creaciones de este artista, que sin hacer referencia a la Antigüedad clásica yacen sin embargo distintos sistemas sociales arcaicos y etapas del desarrollo matriarcal y patriarcal: "Las huellas de la memoria ficticia representan así una utopía regresiva recortada sobre el horizonte de Nueva York"' (Schneckenburger, 1998: 569).

Las Ciudades enteras de Max Ernst evocarían un mundo mítico, careciendo de una localización topográfica precisa, se alzan sobre una montaña presentando una arquitectura futurista a la que se accede mediante una serie de rampas. En La ciudad entera de 1935 y 1936, la ciudad se convertiría en un símbolo ascensional en donde se remarca más este sentido con el sol que corona la composición, llevando al espectador hacia la cúspide.

\section{El cuadrado y el trazado de la ciudad.}

La manifestación solidificada se expresaría mediante el cuadrado, como la civilización que se representaría mediante la forma cuadrada de la ciudad. J. Chevalier y A. Gheerbrant afirman como la construcción de las ciudades era primitivamente imputada a Caín (Gén 4.17), siendo un signo de sedentarización de los pueblos nómadas, definiendo este hecho como una verdadera cristalización cíclica, siendo esta la razón por la que las ciudades serían tradicionalmente cuadradas, símbolo de estabilidad, mientras que las tiendas o los campamentos nómadas serían por lo general circulares, símbolo de movimiento, de aquí que la Jerusalén celestial sería cuadrada:

Las ciudades establecidas en el centro del mundo, reflejan en el orden celestial y reciben sus influencias. Son también en ciertos casos, y por idéntica razón, imágenes de centros espirituales. Así ocurre con la Heliópolis primordial, ciudad del sol; con Salem, la ciudad de la paz; con la Luz, almendro de Jacob llamó Beith-el (casa de Dios). El nombre de Heliópolis evoca naturalmente el simbolismo zodiacal. Por otra parte se recordará que la Jerusalén celestial posee doce puertas (tres a cada oriente), que corresponde manifiestamente a los doce signos, y a las doce tribus de Israel (Chevalier, 1999: 309).

En China el espacio sería cuadrado de manera que cada oriente estaría dominado por una montaña cardinal, la forma cuadrada de la Tierra sería una idea muy antigua inscrita en la lengua. Así el espacio estaría definido por las cuatro direcciones yang, pero este término significa también cuadrado. Por esta razón el Dios del suelo se representa por un túmulo cuadrado, la capital 
es cuadrada, el dominio real también, etc. El espacio estaría así constituido por cuadrados encajados unos en otros (con relación al centro del mundo) o yuxtapuestos alrededor de centros secundarios. La ciudad china sería centro del espacio, siendo cuadrada, con cuatro puertas cardinales. Los vasallos eran recibidos en la ciudad en las cuatro puertas, reuniéndose formando un cuadrado que representaría el restablecimiento del buen orden del mundo.

J. Chevalier y A. Cheerbrant dicen como el simbolismo cuadrado de la ciudad se patentizaría en el caso de la reconquista de Valencia:

Agujereados los muros de dicha ciudad por las tropas de Jaime I y vencidos los moros con la ayuda principalísima de los caballeros leridanos, el rey otorga a la nueva ciudad cristiana las leyes y ordenaciones de la ciudad de Lérida, así como los símbolos de su nuevo escudo, y concretamente las dos L que flanquean en ambos lados. Estas dos letras, que encabezan el nombre catalán de la ciudad madre (Lleida) son el símbolo de la doble escuadra que equivale al cuadrado (Chevalier, 1999: 373).

Según estos autores dar este símbolo a la nueva urbe sería darle "el patrón y la forma", realizándose todo esto en los aspectos más pragmáticos y materiales, ya que hasta época reciente los síndicos valencianos acudían anualmente a Lérida para recibir y comprobar las medidas y los pesos.

Esta forma cuadrangular se adoptaría para delimitar numerosos sitios, tales como la plaza pública de Atenas, mientras que en la Edad Media se edificaban ciudades cuadradas como Sainte-Foy, Montpazier, etc. J. Chevalier y A. Gheerbrant señalan como en la actualidad por el progresivo olvido de las formas tradicionales, se va perdiendo y destruyendo el límite o muro cuadrado de la ciudad:

El ilimitado crecimiento urbano que la negación del símbolo cuadrado determina -y que se patentiza especialmente en las metrópolis, crecidas como manchas de aceite- ha sido caracterizada en las ciencias sociales como una pérdida de la identidad o del centro, que como es sabido genera innumerables e insolubles problemas de control, gobierno, ordenación y planeamiento. El cuadrado, que no se refleja ya en el contorno de la urbe moderna, perdura sin embargo en su trama, cada vez que el planeamiento clásico o racional (también llamada hipodámico) extiende su cuadrícula uniforme para agrupar las casas en manzanas o cuadras (así por ejemplo en el Ensanche Cerdà de Barcelona) (Chevalier, 1999: 375). 
Estos autores dicen como tales casos pondrían de relieve como cualquier pensamiento racional y ordenador de la ciudad no podría olvidar la presencia del símbolo inherente a ella. Esta misma concepción se puede apreciar en la obra de Otto Herbert Hajek que entre 1973 y 1977 realizó Adelaida una obra urbana donde vemos una iconografía con el escudo de la ciudad, con jardín artístico y estructuras del suelo, siendo el cubo y la sección cuadrada la que predomine en su trazado, con patrones de cuadrículas y líneas geométricas.

Paul Klee realizará un viaje a Egipto entre 1928 y 1929, que dará lugar a una serie de obras al óleo con colores brillantes, donde la ciudad será el motivo principal de obras como Una página del libro de la ciudad de 1928 o Calle principal y calle secundaria de 1929, en esta última pintura el artista representa el paisaje urbano mediante una composición estructurada con gran precisión y una arquitectura monumental de formas geométricas, donde el cuadrado y el rectángulo se hallan presentes en perspectivas entrecruzadas y sobrepuestas.

Dalí en su obra pictórica Afueras de la ciudad paranoico-crítica: tarde a la orilla de la historia europea realizada en el año 1936, utilizará el cubo como elemento compositivo. El cubo tendría que ver con el cuadrado, ya que al proyectarse en otro segundo cuadrado a la misma distancia que la longitud de uno de sus lados daría origen a un cubo, ya que la formación de otros cuatro cuadrados construirían dicho cubo.

Georgia O'Keefee representará la ciudad de Nueva York mediante las fachadas de los edificios, que aparecen como superficies trapezoidales con líneas convergentes que se precipitan hacia la base, la pintora no se centrará en las construcciones particulares en sí mismas, sino que las esquematiza mediante una estructura cuadrangular que se eleva hacia el cielo. B. Benke explica así esta serie de los años veinte:

En las formas simplificadas, reducidas a su estructura geométrica básica, en las líneas claras y en las superficies lisas y pulidas se manifiesta la conexión con el preciosismo, la versión realista norteamericana de los años veinte (Benke, 2005: 39).

En El hotel Shelton, Nueva York, $n^{\circ} 1$ de 1926, el cuadrado y el rectángulo serán fundamentales a la hora de componer el edificio al que muestra desde abajo, como si estuviera visto al ras del suelo, mediante este punto de vista y el formato alargado, la pintora destacará la verticalidad del edificio. 
Anne y Patrick Poirier en 1971 convertirán antiguos yacimientos arqueológicos en representaciones arquetípicas que evocan desde la villa romana de Adriano hasta la arquitectura de Claude-Nicolas Ledoux. En su obra de 1975 y 1976 titulada Ausée, Black City (Ciudad negra), realizan una ciudad en ruinas con carbón, corcho y un fregadero donde el trazado cuadrangular domina la composición. M. Schneckenburge nos introduce en este tipo de obra:

La oscuridad de la noche, el brillo del agua y los laberínticos pasillos traen a la memoria los "mitos, sueños y deseos de un subconsciente colectivo". La célebre analogía freudiana de la arqueología y la psique, de las ruinas y la amnesia adopta la forma de una arquitectura fantástica (Schneckenburger, 1998: 568).

D. Maclagan señala que al igual que el hombre sería el foco del cosmos en ciertos mitos del origen, complementándolo y dándole un sentido, el artista sería para este autor como un colaborador en el proceso creativo, ya que en cierto modo, el artista dedicaría su arte a elaborar su propia mitología individual, de forma que las imágenes recurrentes de su obra tienden a revelar los temas que se vislumbran en los mitos sobre el origen:

Las más frecuentes son la desintegración del yo: un cierto "caos", o lo que es lo mismo una ruptura con las convenciones sociales, sexuales y culturales que conduce después a una identificación con el mundo o con cualquiera de sus partes, nueva, "original" (Maclagan, 1994: 9).

\section{Símbolos transcendentales ligados a la ciudad.}

Los temas imaginarios de la ciudad que los artistas recrean en sus obras a pesar de ser universales, intemporales y estar dentro del mundo arquetípico del artista, serán muy distintos según los creadores, ligándose este arquetipo con otros símbolos, con los que suele aparecer y se relaciona. Así enlazando con el arquetipo de la ciudad aparece el del castillo, símbolo de protección y trascendencia. La Jerusalén celeste, toma la forma de un fuerte lleno de torres y agujas, situada en la cima de una montaña. René Magritte representará este símbolo en El castillo de los Pirineos de 1959, aquí el castillo está sobre un gran casco rocoso que flota sobre el mar.

El castillo se convierte en un símbolo de protección y está situado en las alturas, siendo una morada sólida y de difícil acceso, de igual modo la ciudad circular volante de Jonatan Switf aparece como una isla volante llamada "Lapu- 
ta" que era conducida por un grupo de inventores lunáticos con la ayuda de una rueda del tiempo magnética y que acabó en parodia de la "Royal Society", en su obra Gullivers Reisen (Los viajes de Gulliver) de hacía 1910 (fig. 1).

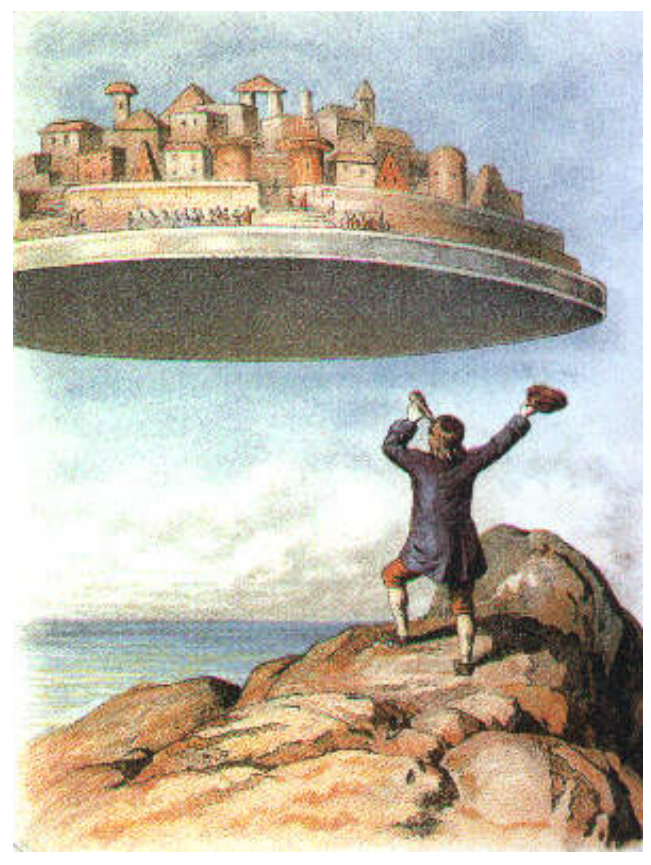

Fig. 1. Jonatan Switf, Gullivers Reisen (Los viajes de Gulliver) de hacía 1910. http://www.geocities.ws/pensamentobr/ mapashtml.html (CC BY-NC-ND 2.5)

Para Giorgio de Chirico la ciudad como arquetipo estaría ligado a la dimensión del paisaje ferrarés, el fundador de la llamada pittura metafisica, pintará obras como Las Musas inquietantes de 1917 y 1918, reflejando una soledad perpleja donde el artista transmite un misterio a través de objetos situados en plazas solitarias. El arquetipo de la torre será frecuente en este periodo artístico comprendido entre 1911 y 1918 donde este símbolo aparece en obras como La torre roja de 1913 o La nostalgia del infinito del mismo año. En esta última obra la torre se sitúa en una atmósfera onírica que logra mediante una composición donde una perspectiva irracional se combina con la falta de una fuente de luz unificada y que el artista potencia con una prolongación de las sombras y de un enfoque alucinatorio de las figuras.

En Giorgio de Chirico la torre fijada sobre el centro (centro del mundo), sería un símbolo ascensional, donde sus edificios, sus plazas se convierten en 
símbolos de complementarismo psíquico, ejerciendo una influencia específica en el espectador que contempla estos espacios urbanos alucinantes.

En el simbolismo de la orden cisterciense la torre se relaciona con una ciudad fortificada rodeada de muros y de torres que ponen al abrigo de las sorpresas enemigas, así la pobreza formaría los muros, y el silencio formaría una torre que eleva el alma hacia Dios. En la alquimia el atanor tomaría la forma de torre, significando las transmutaciones perseguidas en todas las operaciones que tendrían un sentido de elevación. El alquimista Valentín Weigel escribía en su obra Azoth E Ignis de 1787: “La nueva Jerusalén será eternamente un cristal de antimonio rojizo y transparente como una piedra (preciosa): es el nuevo cielo y la nueva tierra, donde moraremos todos nosotros" (Roob, 1997: 342).

Las esculturas de Richard Serra de placas rectas y curvadas realizadas en acero corten, incluirían coordenadas de planos urbanos, edificios y situación espacial, donde sus obras representan arquetipos relacionados con la ciudad. Para M. Schneckenburger (1998: 542-543):

Estas obras modifican las condiciones de percepción, convirtiendo el espacio en escultura y la escultura en espacio. Estas esculturas esclarecen los vagos contextos de los núcleos circulatorios urbanos, contrarrestándolos, cargándolos de tensión y condensándolos en energía escultural: una estrategia ofensiva de afirmación en el corazón de la necesidad urbana.

Richard Serra realizará una gran columna a la que titula Terminal realizada entre 1976 y 1977, mediante cuatro placas de acero corten. La columna al igual que la torre sería un símbolo ascensional, la columna o pilar en las tradiciones célticas era un símbolo del eje del mundo al igual que ocurre con el árbol de la vida. La columna indica límites y flanquear puertas, marcando el paso de un mundo a otro. En el judaísmo y cristianismo la columna tiene un simbolismo cósmico y espiritual, ya que, al sostener lo alto tiene la función de conectar lo bajo con lo alto como ocurre con la columna en las catedrales góticas.

A partir de 1972, Serra intervendrá en el paisaje urbano, así en Shift, al norte de Toronto, señaló y desarrolló toda una colina hasta donde alcanza la vista, para ello utilizó seis muros de longitud idéntica. La colina sería el lugar de emplazamiento que Richard Serra utiliza para situar su obra, las líneas suaves de la colina pondrían a este símbolo acorde con un aspecto de lo sagrado que sería la medida del ser humano, siendo la primera manifestación de la crea- 
ción del mundo, ya que sobresale lo suficiente como para diferenciarse del caos inicial, marcando el comienzo de una emergencia y diferenciación. Para los egipcios sería un símbolo de lo que emergió en primer lugar del caos, cuando el aire sopló en la tempestad por encima de las aguas primordiales.

Estas esculturas al aire libre de carácter monumental con placas de acero que parecen cruzarse con los elementos que nos rodean estarían demarcando igual que en épocas anteriores esos límites sagrados que tanta importancia tuvieron en la antigüedad. El escultor estadounidense dice de su obra:

Mi decisión anterior de construir obras en acero específicas para una ubicación determinada me hizo salir del estudio tradicional. El estudio ha sido sustituido por el urbanismo y la industria (Fricke et al, 1998: 542).

En esta misma línea Reiner Ruthenbeck en 1977, emplea el simbolismo del número siete, mediante su obra titulada Siete Barreras negras, donde demarca el paisaje urbano en Bundesgartenschau con unos mástiles de aluminio y hierro. El símbolo del mástil será utilizado en innumerables culturas, como el mástil que atravesaría en la India la amalaka que figuraría la puerta del sol, mientras que en las fiestas hindúes de Indradhvaja se levantan mástiles que se identificarían con Indra. C. G. Jung afirma como el artista recaería una y otra vez sobre figuras mitológicas, a fin de expresar adecuadamente su interioridad creando a partir de la vivencia primordial, cuya oscura naturaleza precisa de las figuras mitológicas:

La vivencia primordial carece de palabras e imágenes, pues es una visión "en el espejo oscuro". Es meramente poderosísimo presentimiento, que quisiera llegar a la expresión. Es como un torbellino de viento que capta todo lo que se le ofrece y, arremolinándolo hacia arriba, gana con ello figura visible (Jung, 1990: 17-18).

\section{La ciudad como símbolo social y divino relacionado con la cuaternidad, como imagen del mundo interior del ser humano.}

En Roma, en Angkor, en Pekín y en todos los países de influencia china, tendrían en sus ciudades dos vías perpendiculares que unirían las cuatro puertas cardinales, haciendo que el plano de la ciudad se asemejara a un mandala cuaternario simple de Shiva. La ciudad divina Brahmapura sería también una designación del corazón, del centro del ser en donde reside Purusha el Principio descendente y que se manifiesta. Esta misma simbología es usada 
por el patriarca zen Huei-nēng cuando dice que el cuerpo sería la ciudad, siendo sus sentidos las puertas, y el rey que allí reside sería el Sí, el sing o la "naturaleza propia".

G. Champeaux afirma que desde las épocas vecinas de la prehistoria el cuatro se utilizaría para significar lo sólido, lo tangible, lo sensible: "Su relación con la cruz hace de él un símbolo incomparable de plenitud, de universalidad; un símbolo totalizador" (Chevalier, 1999: 380). Para C. G. Jung la cuaternidad sería uno de los arquetipos más universales y se revelaría como uno de los esquemas estructurales más útiles para las funciones de orientación de la consciencia, este arquetipo lo relaciona con la cruz formada por los cuatro puntos angulares y el círculo, como símbolo de la perfección y del ser perfecto, siendo una expresión muy difundida en todas las culturas del cielo, del sol, de Dios y del arquetipo del hombre y del alma.

El número cuatro como número plural mínimo representa el estado pluralista del hombre que no ha alcanzado la unidad interior, esto es, el estado de la falta de libertad, de la no identificación consigo mismo, de la dispersión, del desgarramiento en tendencias contrapuestas; es decir, una situación penosa, no resuelta, que busca la unidad, la conciliación, la libertad, la curación, o sea, la integridad (Jung, 1993b: 71).

La simbólica del cuadrado y la del número cuatro se relacionan, los pitagóricos hacían de la Tetraktys y del cuadrado de cuatro, es decir, dieciséis, la base de su doctrina. El número cuatro encarnaría la perfección divina, siendo el número del desarrollo completo de la manifestación y símbolo del mundo estabilizado. Este desarrollo se efectuaría a partir del centro inmóvil a partir de la cruz de las direcciones cardinales. De manera que la cruz en el cuadrado sería la expresión dinámica del cuaternario. La cuaternidad sería un arquetipo que se presentaría universalmente:

Es la premisa lógica de todo juicio de totalidad. Si se quiere llegar a un juicio de este tipo, éste debe tener un aspecto cuádruple. Cuando por ejemplo, se quiere caracterizar la totalidad del horizonte, se nombran los cuatro puntos cardinales. Hay siempre cuatro elementos, cuatro cualidades primitivas, cuatro colores, cuatro castas en la India, cuatro caminos en el sentido de evolución espiritual en el budismo (Jung, 1996: 412).

Las ciudades chinas eran cuadradas y tenían cuatro puertas cardinales por las que se expulsaban las malas influencias, acogiéndose las buenas. Por estas 
puertas se recibía a los huéspedes, extendiéndose a las cuatro regiones del imperio la virtud imperial y se regulaban las horas del día y las estaciones. Las cuatro puertas de AngKor-Thom repetiría a los cuatro orientes la efigie radiante de Lokeshvara soberano del universo, permitiendo el acceso, desde las cuatro direcciones, a este centro del mundo. La puerta simbolizaría el lugar de paso entre dos estados, entre dos mundos, entre lo conocido y lo desconocido, abriéndonos a un misterio, indicando un pasaje que invite a atravesarlo.

La puerta es la abertura que permite entrar y salir, y por tanto el pasaje posible -aunque único- de un dominio a otro: por lo general, en la acepción simbólica, del dominio profano al dominio sagrado. Así el pórtico de las catedrales, los torana hindúes, las puertas de los templos o de las ciudades Khmers, los torii japoneses, etc. (Chevalier, 1999: 855).

En la India los cuatro orientes corresponderían simbólicamente a las cuatro castas que tendrían una importancia en la vida religiosa y social, quedando todo esto reflejado simbólicamente en la configuración de la ciudad. Sri Aurobindo nos acerca a la institución védica del "orden cuaternario" o catuvarna, denominado erróneamente sistema de las cuatro castas de la India, explicando que mientras la casta sería una institución convencional, varna sería una institución simbólica configurada sobre la base de los tipos psicológicos.

Para ellos el símbolo del cuerpo del Creador era algo más que una imagen: expresaba una realidad divina. La sociedad humana era un intento de expresar en esta vida el Purusha cósmico, que se manifiesta de forma diferente en el universo material y en el suprafísico. Hombre y Cosmos eran ambos símbolos y manifestaciones de una misma Realidad oculta (Aurobindo, 2002: 25-26).

Esta distinción cuatripartita gobernaría el urbanismo ya que a cada estado o casta estaría reservada una de las regiones cardinales de la ciudad, a los sabios el norte, a los guerreros el este, a los negociadores el sur y a los servidores el oeste. J. Chevalier y A. Gheerbrant dicen que para los analistas no se excluiría que estas divisiones sociales, cósmicas e históricas corresponderían a tendencias, grados de estructura o fases de evolución que se encontrarían en la vida interior del individuo:

Las castas hindúes no son solamente, como se admite en general, un fenómeno de organización social de tipo ario y el instrumento de un orden jerárquico o de una segregación. Expresan simbólicamente una repartición de las funciones que es propia tanto de las actividades divinas como de la existencia de una so- 
ciedad o de un individuo. Pues la complejidad del ser humano hace de éste una sociedad en miniatura. Desde tales puntos de vista el principio de las castas toma valor universal (Chevalier, 1999: 260).

C. G. Jung dice como habría también cuatro aspectos psicológicos de la orientación psíquica:

Debemos tener, como orientación, una función que compruebe que hay algo (sensibilidad), una segunda que verifique qué es esto (pensamiento), una tercera función que diga si esto se adecua o no, si se quiere admitir o no (sentimiento) y una cuarta que indique de dónde viene y adónde va (intuición). Más allá de ahí ya no se puede decir nada... La perfección ideal es lo redondo, el círculo, pero su escala mínima es la cuadratura (Jung, 1996: 412-413).

Sri Aurobindo afirma como todas las instituciones religiosas y sociales de la India védica, los momentos y fases de la vida del individuo, eran para él símbolos mediante los cuales trataría de expresar lo que conoce o adivina de las influencias místicas que se ocultarían detrás de la existencia del hombre, modelando y rigiendo sus movimientos e incluso interviniendo secretamente en ellos. De esta actitud simbólica nació la tendencia de hacer de todo en la vida social un sacramento. En este caso la idea espiritual lo gobernaría todo, las formas religiosas simbólicas que la sostienen son en principio fijas, mientras que las formas sociales son imprecisas, libres y capaces de un desarrollo ilimitado. Frente a esto el tipo psicológico experimentaría una fijación progresiva, teniendo una concepción simbólica de los cuatro órdenes que se expresarían respectivamente como el Divino como conocimiento en el hombre, el Divino como poder, el Divino como productividad, intercambio y gozo, el Divino como servicio, obediencia y trabajo.

Estas divisiones corresponderían a cuatro principios cósmicos: la Sabiduría que concibe el orden y el principio de las cosas, el Poder que lo sanciona, lo apoya y lo impone, la Armonía que genera la ordenación de las partes, el Trabajo que ejecuta lo que el resto dirige. Partiendo de esta concepción, se desarrolló un orden social estable, pero no rígido todavía, basado principalmente en el temperamento y el tipo psíquico (guna) con su correspondiente disciplina ética y subsidiariamente en la función social y económica (Karma). La función quedaba determinada por su afinidad con el tipo psíquico y por su utilidad para la disciplina ética, no siendo el factor único ni el principal. La primera etapa de esta evolución, la etapa simbólica, es predominantemente religio- 
sa y espiritual, los demás elementos psicológicos, éticos, económicos y físicos, se encontrarían presentes, pero estarían subordinados a la concepción espiritual y religiosa. Esta etapa arquetípica es definida por este autor como psicológica y moral, todos los elementos, incluso el espiritual y el religioso, estarían subordinados a la concepción psicológica y al ideal moral que lo expresa:

La religión se convierte entonces en una sanción mística del principio y la disciplina moral, del Dharma, lo que constituirá en adelante su utilidad social fundamental. Por otra parte, la religión se va orientando cada vez más hacia lo ultraterreno y la idea de expresar al Ser divino y el Principio cósmico directamente en el hombre deja de ser una noción dominante o rectora; retrocede, pasa a un segundo plano y finalmente desaparece no sólo de la práctica sino también del planteamiento teórico de la vida (Aurobindo, 2002: 26-27).

A la etapa arquetípica se debe la creación de grandes ideales sociales que han dejado su impronta en la mente humana y que sobreviven tras pasar dicha fase. Ejemplo de ello es el ideal del honor social que Sri Aurobindo divide en la siguiente manera: El honor del brahmán que residiría en la pureza, en la piedad, en la profunda veneración por cuanto pertenece a los ámbitos mental y espiritual, junto con la búsqueda exclusiva y desinteresada de la erudición y el conocimiento. El honor del kshatriya basado en el valor, la caballerosidad, la fuerza, en una orgullosa templanza y dominio de sí, en la nobleza de carácter y las obligaciones que ella le impone. El honor del vaishya que se expresaría por la rectitud en los asuntos económicos, la fidelidad comercial, la producción honesta, el orden, la tolerancia y la filantropía. El honor del shudra basado en la obediencia, la subordinación, el servicio fiel, el afecto desinteresado.

Con el tiempo estas cualidades dejarían de hundir sus vivas raíces en una concepción psicológica clara y ya no brotarían de forma natural de la vida interior del hombre, sino que se convierten en mera convención a pesar de que sean la más noble de las convenciones, convirtiéndose finalmente en una tradición en el pensamiento y el discurso que en una realidad en la vida. Todo esto desembocaría en la etapa convencional de la sociedad humana que se traduciría en que los soportes exteriores, las expresiones superficiales del espíritu o del ideal, pasan a ser más importantes que el ideal en sí mismo:

... cuando el cuerpo, o hasta las propias vestiduras, adquieren mayor importancia que la persona. Por eso, los soportes exteriores del orden cuaternario ético -nacimiento, función económica, rituales y sacramentos religiosos, costum- 
bres familiares- comienzan a adquirir una importancia y unas proporciones desmesuradas en la evolución del sistema de castas (Aurobindo, 2002: 27).

Estos periodos convencionales de la sociedad contienen, a pesar de todo, como dice Sri Aurobindo elementos realmente bellos, sanos y útiles para el progreso de la humanidad, pero no por ello la Verdad ha sido realizada, ni consumada, siendo la forma artística la que viene a suplir su escasez e imita su manifestación más plena. Aurobindo señala como la fase subjetiva del desarrollo humano, sería un momento crítico en el que superados los símbolos, los tipos y las convenciones, se estudiaría superficialmente al ser individual:

... para descubrir su verdad y la ley correcta de su acción en relación con la verdad y la ley superficiales y exteriores del universo, el hombre comienza a mirar más profundamente y a ver y a sentir lo que está detrás de las apariencias y debajo de la superficie, y, en consecuencia, vivir desde el interior (Aurobindo, 2002: 63).

La edad individualista surgiría en la sociedad humana debido a la corrupción y el fracaso de la edad convencional, como rebelión contra el reinado de las formas arquetípicas petrificadas. Sri Aurobindo señala que es menester para que su nacimiento sea posible, que las antiguas verdades se hayan extinguido en el espíritu y en los usos y costumbres del género humano y que incluso las convenciones que las imitan y remplazan se hayan vaciado del significado real, tornándose ininteligibles. Estas verdades carentes ya de toda justificación práctica, sólo existirían de manera mecánica, por la inercia de las ideas, la fuerza de la costumbre y el apego a las formas. Cuando esto ocurre, el ser humano no puede dejar de percibir finalmente que "la Verdad" ha muerto en estas verdades, viviéndose en la mentira. El individualismo intentaría en esta nueva etapa, librarse de las creencias y prácticas convencionales y recuperar los fundamentos sólidos de una verdad real y tangible. Esta nueva tentativa se caracterizará por ser individualista, ya que al haberse derrumbado, ya no proporciona ninguna ayuda interior. Será el individuo el que deberá hacer de explorador y pionero, emprendiendo la búsqueda de la verdadera ley del mundo y de su propio ser, con la ayuda de su razón, intuición, idealismo, con sus anhelos y aspiraciones vitales, o con el auxilio de cualquier otra luz que pudiera encontrar en sí mismo:

Cuando haya encontrado la ley verdadera (o cuando crea haberla encontrado), tratará de cimentar sobre una base sólida la religión, la sociedad, la ética, las 
instituciones políticas, las relaciones interpersonales, sus esfuerzos en pos de la perfección y su labor en pro de la humanidad, procurando remodelar todo ello en unas formas más vitales, aun cuando puedan resultar más pobres (Aurobindo, 2002: 32-33).

La ciudad siempre ha encarnado este tipo de ideales como vemos en la obra de Richard Brothers que combina convicciones radicalmente democráticas con tradiciones bíblicas y sus propias experiencias visionarias, identificando la Jerusalén conquistada con el Londres de su época. Dibujó en un plano detallado de la futura ciudad basándose en las indicaciones del profeta Ezequiel (fig. 2). A. Roob dice como Richard Brothers profetiza:

... la caída de la urbe británica en el caso de que la alianza monárquica ganara la guerra contra la Francia republicana. En este caso, la nueva Jerusalén no caería del cielo, sino que sería nuevamente construida en Palestina de su tiempo (Roob, 1997: 341).

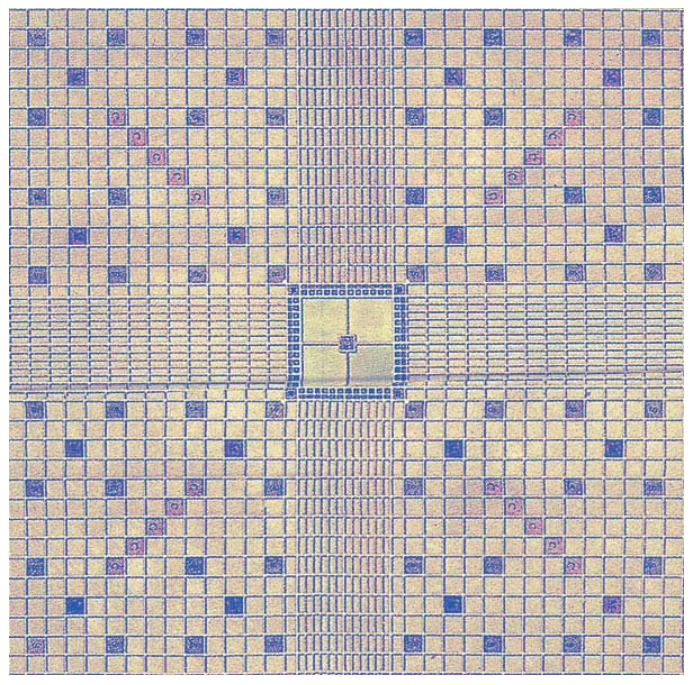

Figura 2. Grabado de Wilson Lowry, en Richard Brothers, Descriptión of Jerusalem, 1801 (Fuente: http://kokanddeiman. $\mathrm{com} / \mathrm{np} 3 /)$

William Blake en su poesía nos da los datos topográficos de "Golgonooza" la ciudad de las artes y de la artesanía, donde cada una de las puertas se abría a todas las demás hacia los cuatro puntos cardinales, de forma que todas están contenidas en cada una de estas puertas: "En el cerebro y el corazón y la pelvis se abren puertas detrás de la sede de Satán en la ciudad de Golgonooza, que es la Londres de diversidad religiosa en la pelvis de Albión (Roob, 1997: 338). 
Roob dice que el nombre de "Golgonooza" estaría compuesta de "Gólgota" o colina de cráneo, "ooze" o fango y "noose" o nudo. Esta ciudad tendría en su puerta este, el nido de las alondras que serían las mensajeras de Los o personificación de la energía creadora. En el centro estarían los herreros y sus fraguas, mientras que al lado estarían los telares de su esposa y la puerta de "Luban", símbolo de la matriz. Esta ciudad de W. Blake con sus cuatro dimensiones estaría construida delante de la Jerusalén, lugar de culminación y libertad, donde la energía creadora o Los, volverá a crear la ciudad como bastión contra el mundo fantasmal de tres dimensiones al que llama "ulro" o "tierra de la muerte eterna".

Para Sri Aurobindo el principio fundamental del individualismo es el de la libertad del ser humano para desarrollarse y realizar su vida, satisfaciendo sus tendencias mentales y su ser físico. El fin inherente de toda edad individualista de la humanidad tendría su origen en la necesidad imperiosa de redescubrir las verdades esenciales de la vida, del pensamiento y de la acción, que se encuentran velados por la falsedad de los principios convencionales. Sri Aurobindo dice que mientras en Europa nació la edad del individualismo y es donde ha ejercido su pleno predominio, Oriente ha participado de ella por contacto y por influencia y no por impulso original. No obstante este autor considera que las verdades que Europa ha descubierto en su edad individualista no abarcarían más que los hechos exteriores de la vida, es decir los más evidentes, los más físicos y superficiales, además de las realidades y fuerzas escondidas tras el fenómeno externo. Y sólo han llegado a conocer aquellas que pueden serle reveladas por los hábitos de la razón analítica y en la búsqueda de la utilidad práctica. Si la civilización racionalista europea ha barrido triunfalmente el mundo, se debería como dice Sri Aurobindo (2002:33)

... a que no ha encontrado en su camino otra verdad más profunda y poderosa que pudiese hacerle frente, pues el resto de la humanidad estaba aún sumido en la pasividad de las últimas horas sombrías de la edad convencional.

Según Sri Aurobindo el periodo individualista de la sociedad debe fijarse imperativamente como meta la consumación de dos objetivos supremos:

1. Encontrar un principio general de Verdad que todo juicio individual se sienta interiormente obligado a aceptar sin que medie coacción física alguna ni imposición por parte de una autoridad irracional. 
2. Descubrir un principio de orden social que, análogamente, deberá fundarse en una verdad universalmente verificable.

Este autor señala como sería necesario un orden que ponga freno a las apetencias e intereses, aportando al menos algún criterio intelectual y moral que estas dos fuerzas deben acatar para poder sentirse justificadas a la hora de afirmar sus reivindicaciones vitales:

Las naciones progresistas de Europa iniciaron la búsqueda de esta luz y de esta ley, adoptando como medio la razón especulativa y científica y, como principio, la consecución de una justicia social práctica y de un sólido utilitarismo (Aurobindo, 2002: 37-38).

Sri Aurobindo señala como la sociedad individualista de Europa, al descubrir al individuo, ha fijado dos ideas entre las ideas fuerzas del futuro que no podrán ser eliminadas por ninguna reacción temporal:

1. La idea democrática del derecho de todos los individuos como miembros de la sociedad a una vida digna y a un desarrollo tan completo como sean capaces de alcanzar.

2. El individuo no sería solamente una unidad social. Su reivindicación de vida y crecimiento, no se fundan solamente en su trabajo y en su función social.

Sri Aurobindo señala como este último punto sería una verdad que Europa habría reconocido intelectualmente y a la que habría:

... conferido su plena significación exterior y superficial, que concuerda en su raíz con las concepciones espirituales más elevadas y más profundas de Asia, $\mathrm{y}$, que, en consecuencia, debe jugar un importante papel en la configuración del porvenir (Aurobindo, 2002: 43).

Para Sri Aurobindo el hombre no es sólo un miembro de un agregado humano, "de una colmena o de un hormiguero", sería algo en sí mismo, un alma, un ser que debe realizar su verdad y su ley individuales. Realizando igualmente su parte, natural o asignada, en la verdad y en la ley de la existencia colectiva. El ser humano reclamaría libertad de espacio, iniciativa, para su alma y su naturaleza, para un pensamiento, una voluntad y una consciencia individuales. Una fuerza subjetiva más grande siempre ha estado detrás de los individuos, la política, los movimientos económicos y los cambios institu- 
cionales. Esta fuerza actúa, sobre todo, de forma subconsciente, como entidad subliminal que como pensamiento consciente.

Sólo cuando el poder del alma colectiva sale del subconsciente y asciende a la superficie, comienzan las naciones a tomar posesión de su yo subjetivo; aunque sea de forma vaga e imperfecta, están ya en camino hacia su alma (Aurobindo, 2002: 56).

La ciudad encarnaría el mundo social como imagen del mundo divino, el mundo interior del ser humano sería la imagen de la sociedad que se organizaría espacialmente en el símbolo de la ciudad, siendo desde tiempos inmemoriales, el arquetipo de la totalidad perfecta, como dice C. G. Jung (1995: 417):

...capaz de imponerse por su propia potencia frente a todas las influencias disgregantes, el símbolo de la existencia eterna, como la celeste Jerusalén, que encarna la plenitud de los cielos, un estado duradero fuera del alcance del tiempo.

Georg von Welling en su Opus mago-cabalisticum de 1760, interpretará el Apocalipsis de San Juan, diciendo que Cristo creará un nuevo mundo con la nueva Jerusalén, la ciudad será creada sobre el globo terrestre, a la medida del hombre en su semejanza con Dios "como réplica de la ciudad arquetípica de Dios" (Roob, 1997: 343). En el arte, la ciudad cobraría vida en una simbología perteneciente a la mitología tratándose de una manifestación psíquica que reflejaría la naturaleza del alma, estas imágenes atraen, convencen y fascinan al espectador que a través de estos símbolos conectaría con su esencia más profunda, pues como dice C. G. Jung:

Deben atraer, convencer, fascinar, dominar. Han sido creadas de la materia virgen de la revelación y reflejan la experiencia primera de la divinidad. Por eso abren al hombre al presentimiento de lo divino y al mismo tiempo lo ponen a cubierto frente a la experiencia inmediata de la divinidad (Jung, 1994: 14).

\section{La unión de los contrarios y la ciudad.}

La ciudad en las manifestaciones artísticas se puede presentar como un símbolo unificador de los contrarios, del consciente y el inconsciente, siendo un reflejo de los procesos psicológicos y fisiológicos del individuo. Para D. Maclagan el consciente y el inconsciente se encontrarían en equilibrio activo y dialectico: "A lo largo de nuestras vidas somos testigos forzosos de su contradicción en todos los ámbitos y aun así nos esforzamos por vislumbrar su resolución definitiva." (Maclagan, 1994: 74). Los contrarios son definidos por Sri 
Aurobindo como dos movimientos cuya aparente contradicción puede confundir nuestra mente, pero que serían los dos extremos de una sola consciencia cuyos movimientos se encuentran separados en el hombre uno del otro, debiendo unirse, siendo la misión del "poder-de-vida" del ser humano una culminación cada vez más y más perfecta o su transformación tan esperada:

El ser vital con la fuerza-de-vida en él es uno de estos extremos; el otro es un poder dinámico latente en la consciencia superior a través del cual la Verdad Divina puede actuar, influir en el vital y su fuerza-de-vida y usarla para un propósito superior en este plano (Aurobindo, 1995: 17-18).

Rudolf Steiner consideraba como el hombre tan pronto como despertaba en él la consciencia, erigía un muro entre él y el mundo, este autor señalaba como el exceso de lo que en las cosas buscamos, sobre aquello que éstas nos ofrecen de un modo inmediato, dividiría nuestro ser en dos partes, apareciendo el universo en esta polaridad a la que llama "yo y el mundo". Esta oposición sería reconciliada por el sentimiento humano de que no somos seres fuera del universo, sino dentro del mismo y que nunca perderíamos el sentimiento de que pertenecemos al mundo, siendo este sentimiento el que engendraría el esfuerzo que tiende a esta conciliación que consistiría en último término según este autor en todo el esfuerzo espiritual de la humanidad:

La historia de la vida espiritual no es sino una continuada búsqueda de la unidad entre nosotros y el mundo. Tanto la religión, como el arte y la ciencia, persiguen este fin. El hombre de creencias religiosas busca en la revelación que Dios se digna otorgarle, la solución de los enigmas del mundo, enigmas que surgen en su yo, descontento con el mundo de las apariencias. El artista procura incorporar a la materia las ideas de su yo, a fin de conciliar con el mundo exterior lo que vive en su interior. Tampoco a él le satisface el mundo de la mera apariencia, y se esfuerza en moldear en éste aquel exceso que su yo, desbordante del mismo, encierra (Steiner, 2000: 21-22).

Este pensamiento concuerda con R. Lawlor (1993: 45) cuando dice: "Es posible volverse consciente de que extraemos el objeto externo de la totalidad de nuestro espacio interior, fundiendo así la contemplación de uno mismo y del mundo".

René Magritte desde 1948 hasta su muerte pintará una serie de paisajes urbanos donde se unen la dualidad de luz y oscuridad, representando la unión de los contrarios en el arquetipo de la ciudad, como podemos ver en su obra El imperio de las luces de 1953, las casas de la ciudad aparecen entre el follaje, 
iluminadas por la luz eléctrica que se advierte en las ventanas, así como por las que despiden uno o varios faroles en el exterior, esto se contrapone con un cielo azul diurno surcado por nubes blancas, donde el artista pintaría una realidad donde coexistirían al mismo tiempo, la noche en el plano de tierra, frente al día que estaría representada en el plano de aire.

D. Maclan dice como la fuerza motriz de la creación sería la diferenciación, su energía provendría de la tensión entre los contrarios. Así en sumerio la palabra que designaba el universo, an- $k i$, significaría en realidad "cielo-ytierra" y la "imposición de nombre" al ser humano no podía darse hasta que la tierra y el cielo no se hubieran separado, nada creado posee un mundo propio "definirlo es relacionarlo con su opuesto, con su negativo; el desorden se opone al orden, el azar a la necesidad, la mutación a la repetición, la destrucción a la creación" (Maclagan, 1994: 17).

En el pintor belga Paul Delvaux la ciudad se convierte en un escenario, donde los contrarios se representarían por escenas visionarias donde mujeres desnudas frente a hombres vestidos parecen contraponerse en paisajes urbanos llenos de misterio, como podemos ver en su obra El Museo Spizner de 1943.

C. G. Jung señala como la figura del ánima desempeñaría un importante papel en los sueños del individuo, este arquetipo desde tiempos inmemoriales, siempre ha expresado en los mitos la idea de la coexistencia de lo masculino y lo femenino dentro del mismo cuerpo. Según este autor estas intuiciones se proyectan por lo general en la pareja divina, en forma de la syzygia divina, de la pareja divina o en la idea de la naturaleza hermafrodita del Creador. Para este autor habría una personificación de una naturaleza femenina en el inconsciente del hombre y de una naturaleza masculina en el inconsciente de la mujer:

Todo hombre lleva la imagen de la mujer desde siempre en sí, no la imagen de esta mujer determinada, sino de una mujer indeterminada. Esta imagen es, en el fondo, un patrimonio inconsciente, que proviene de los tiempos primitivos $\mathrm{y}$, grabada en el sistema vivo, constituye un Tipo de todas las experiencias de la serie de antepasados de naturaleza femenina, un sedimento de todas las impresiones de mujeres, un sistema de adaptación psíquica heredado... Lo mismo vale para la mujer, también ella tiene una imagen innata de hombre (Jung, 1996: 409-410)

E. Pérez de Carrera afirma como el carácter bisexual del ser humano es uno de los factores que determinan su comportamiento básico: 
Leyenda, deseo y realidad se mezclan en la búsqueda mistérica simbólica endógena y exógena, y ello ha sido y sigue siendo una fuente de conflictos en la que nacen y crecen obsesiones, miedos, alteraciones y riesgos que provocan desconciertos y trastornos que van degradando los neurotransmisores. Esta evidencia condujo a uno de los mayores errores que el hombre ha cometido en estos tiempos, separar el encuentro interior, bautizándolo como camino espiritual, del exterior al que se dio categoría de superficial, intranscendente y mundano (Pérez de Carrera, 2004: 141).

Teilhard de Chardin nos cuenta su experiencia al enfrentarse a los contrarios que, por su educación y por su religión, siempre había admitido hasta entonces, sin reflexionar bien sobre ello, existiendo para este autor una heterogeneidad de fondo entre Materia y Espíritu, Cuerpo y Alma, Inconsciente y Consciente:

... dos "sustancias" de naturaleza distinta, dos "especies" de Ser incompresiblemente asociadas en el Compuesto vivo respecto de las cuales era preciso mantener a cualquier precio, se me aseguraba, que la primera (mi divina Materia) no era sino la humilde sierva (por no decir la adversaria) de la segunda, encontrándose ésta (es decir, el Espíritu) desde entonces reducida a mis ojos, por este mismo hecho, a no ser más que una Sombra que había que venerar por principio, pero por la cual (emotiva e intelectualmente hablando) yo no experimentaba en realidad ningún interés vivo. Júzguese, en consecuencia, mi impresión interior de liberación y júbilo cuando, con mis primeros pasos, aún vacilantes, por un Universo "evolutivo" constataba que el dualismo en el que se me había mantenido hasta entonces se disipaba como la niebla ante el sol naciente. Materia y Espíritu, no dos cosas, sino dos estados, dos rostros de una misma Trama cósmica, según se la vea, o se la prolongue, en el sentido en que (como hubiera dicho Bergson) se hace -o, por el contrario, en el sentido en que se deshace (Teilhard de Chardin, 2002: 28).

Para Sri Aurobindo la vida buscaría el pleno crecimiento del ser humano, pero sus formas infrarracionales estarían remarcadas por la imperfección, la fragmentación y la impermanencia, estando sometidas al impacto de sus opuestos. A lo que habría que añadir que:

... la vida infrarracional conserva todavía el sello del Inconsciente y su insensibilidad fundamental, el espesor de su textura, la debilidad de sus respuestas vibratorias; es incapaz de alcanzar la verdadera felicidad o bienaventuranza (Aurobindo, 2002: 199). 
El artista partiendo de los comienzos infrarracionales se elevaría hacia una consumación suprarracional, pasando por una etapa intermedia en la que dependería de la razón, el ser estético del hombre, iría hacia esa búsqueda del Infinito que se encuentra dentro del ser humano, gozando y moldeándonos en la armonía de su belleza y su felicidad, éste sería el fin de nuestra naturaleza estética. Sri Aurobindo señala como el hombre puede verse a sí mismo como una criatura contenida en el universo, pero cuando llegue al conocimiento, a su verdadero ser-esencial, puede ver también que el universo está contenido en él, sutilmente por implicación de su individualidad, extensamente en el gran ser o "Espíritu universal" con el cual se identifica y se convierte. Desde la antigüedad este conocimiento ha sido proclamado y extendido siendo el arte un medio espiritual puesto al alcance del hombre para que su mente pueda liberarse de su obsesión por la supervivencia y tenga una acción más depurada y desinteresada, cediendo a las motivaciones más sutiles de su naturaleza mental que exige su propio desarrollo interior. André Breton vislumbra esta unión de los contrarios ese punto que concebía "desde el cual la vida y la muerte, lo real y lo imaginario, lo pasado y lo futuro, lo comunicable y lo incomunicable, la altura y la profundidad, ya no se ven como contradictorios"' (Maclagan, 1994: 7).

Según Jung los arquetipos señalarían el camino que debe buscar el hombre para su liberación, el yo consciente estaría subordinado al sí-mismo que constituiría el centro de la personalidad psíquica total, que sería ilimitada e indefinible, no susceptible de formulación y sólo simbólicamente expresable, constituyendo la totalidad del ser humano, tanto en lo consciente como en lo inconsciente.

En todos los artistas estudiados habría una búsqueda de su ser esencial más profundo por medio de este arquetipo universal de la ciudad, que surgiría del inconsciente creador del individuo, ocupando una función de elevación de la consciencia no sólo del creador sino también del espectador que contempla la obra. El artista encontraría muy a menudo en su obra reminiscencias del pasado individual además de numerosas huellas de estadios espirituales arcaicos, estableciendo un enlace con los estratos más antiguos de la historia, donde el arquetipo de la ciudad condensaría la experiencia total del ser humano, representando una síntesis del mundo y del hombre. 


\section{Bibliografía.}

AUROBINDO, Sri. (1995), El enigma de este mundo, Barcelona, Fundación Centro Sri Aurobindo.

AUROBINDO, Sri. (2002), El ciclo humano, Barcelona, Fundación Sri Aurobindo.

CIUfERRI, P. (1979), Los genios de la pintura. Klee, Sarpe, Madrid.

Chevalier, J., GHeERBRANT, A. (1999), Diccionario de los símbolos, Heder, Barcelona.

DESCHARNES, R. NÉRET, G. (2006), Salvador Dalí, La obra pictórica. Tomo I, 19041946, Taschen, Köln.

FAERNA, J. M. (1995), Marc Chagall, Ed. Polígrafa, Barcelona.

Fricke, C. HONNEF, K. RUHRBERG, K. SCHNECKENBURGER, M. (1998), M Arte del siglo XX, Pintura, Escultura, Nuevos medios, Fotografía, Vol. II, Taschen, Köln.

JUNG, C. G. (1990), Formaciones de lo inconsciente, Paidós, Barcelona.

JuNG, C. G. (1992), Psicología y simbólica del arquetipo, Paidós. Barcelona.

JUNG, C. G. (1993 a), Las relaciones entre el yo y el inconsciente, Paidós, Barcelona.

JUNG, C. G. (1993 b), La psicología de la transferencia, Ed. Paidós, Barcelona.

JUNG, C. G. (1994), Arquetipos e inconsciente colectivo, Paidós, Barcelona.

JUNG, C. G. (1995), Los complejos y el inconsciente, Alianza, Madrid.

JuNG, C. G. (1995), AION. Contribución a los simbolismos del sí-mismo. Paidós, Barcelona.

JunG, C. G. (1996), Recuerdos, sueños, pensamientos, Seix Barral, Barcelona.

JunG, C. G. Von Franz, M. L. Henderson, J. L. Jacobi, J. y Jaffé, A. (1997), El hombre y sus símbolos, Ed. Caralt, Barcelona.

LAWLOR, R. (1993), Geometría Sagrada, Debate, Madrid.

MACLAGAN, D. (1994), Mitos de la creación, Debate, Madrid.

PÉREZ DE CARRERA, E. (2004), 49 Respuestas a la aventura del pensamiento, tomo I, Fundación Argos, Madrid.

QUINN, E, (1997), Max Ernst, Ed. Polígrafa, Barcelona.

RoOB, A, (1997), El museo hermético. Alquimia \& Mística, Taschen, Madrid.

StEINER, R. (2000), La filosofía de la libertad, Ed. Antroposófica, Buenos Aires.

TEILHARD DE CHARDIN, P. (2002), El corazón de la materia, Col. Ed. Sal Terrae, Santander.

TARAMELLI, E. (1979), Los genios de la pintura. De Chirico, Sarpe, Madrid.

V. V. A. A. (1996), Mitología. Guía ilustrada de los mitos del mundo, Debate, Madrid. 